\title{
DEFENDIENDO LA ESCLAVITUD EN LAS ANTILLAS, EN LA BARCELONA DEL TRIENIO ESPARTERISTA
}

\author{
DEFENDING SLAVERY IN THE ANTILLES DURING \\ THE PROGRESSIVE TRIENNIUM IN BARCELONA
}

Martín Rodrigo y Alharilla* Universitat Pompeu Fabra, Barcelona, España

\begin{abstract}
RESUMEN: El nombramiento del abolicionista David Turnbull como Cónsul Británico en La Habana y el ataque de la Royal Navy a las factorías negreras españolas en África significaron una vuelta de tuerca más en las presiones británicas abolicionistas frente a España, en un contexto en el que el pro-británico Espartero se había convertido en el hombre fuerte en la política española. El artículo se centra en analizar la campaña antiabolicionista y antibritánica llevada a cabo entonces por el Tribunal de Comercio de Barcelona y por la Junta de Comercio de Cataluña (también por la de Madrid) prestando especial atención a los individuos que lideraron dicha campaña. Se analizan también otros momentos posteriores en los que hubo similares campañas en defensa de la esclavitud en Cuba y en Puerto Rico, en Barcelona, incluso cuando dicha institución había desaparecido de todas las colonias europeas en América, excepto en las Antillas españolas.
\end{abstract}

PALABRAS CLAVE: Cuba, España, Barcelona, Esclavitud, Abolicionismo, Antiabolicionismo.

ABSTRACT: The appointment of the abolitionist David Turnbull as British Consul in Havana and the attack of the Royal Navy on the Spanish factories in Africa represented an increase in pressure against Spain, in a context in which the pro British Espartero had become the leader in Spanish politics. The article focuses on analyzing the anti-abolitionist and anti-British campaign carried out by the Tribunal de Comercio de Barcelona and the Junta de Comercio de Cataluña (also by the Junta de Comercio de Madrid), paying special attention to those who led the campaign. Other subsequent moments in which there were similar campaigns in defense of slavery in Cuba and Puerto Rico in Barcelona were also analyzed, even when slavery had disappeared from all European colonies in America, except in the Spanish Antilles.

KEYWORDS: Cuba, Spain, Barcelona, Slavery, Abolitionism, Antiabolitionism.

* Correspondencia a: Martín Rodrigo y Alharilla, Departamento de Humanidades, Universitat Pompeu Fabra, Calle de Ramon Trias Fargas, 25 08005, Barcelona, España - martin.rodrigo@upf.edu - https://orcid.org/0000-0003-0423-7147

Cómo citar: Rodrigo y Alharilla, Martín (2021). «Defendiendo la esclavitud en las Antillas, en la Barcelona del trienio esparterista»; Historia Contemporánea, 66, 371-401. (https://doi.org/10.1387/hc.21190).

Recibido: 28 octubre, 2019; aceptado: 22 abril, 2020.

ISSN 1130-2402 - eISSN 2340-0277 / (C) 2020 UPV/EHU 
En la España del siglo XIX estuvieron muy presentes tanto la institución de la esclavitud como el comercio de esclavos. En términos comparativos, lo que más llama la atención en la historia española es precisamente la tardía cronología tanto de la supresión efectiva de la trata de esclavos en sus dominios como de la abolición legal de la esclavitud. Sirvan, a título ilustrativo, las siguientes fechas: la institución de la esclavitud en la España peninsular fue plenamente legal, al menos, hasta 1837; la primera Sociedad Abolicionista Española no se creó hasta $1865^{1}$; en la española isla de Cuba, el comercio ilegal de africanos esclavizados se mantuvo hasta 1867 y la primera ley de vientres libres no se aprobó hasta 1870. España fue, de hecho, el último país europeo en ilegalizar la esclavitud en sus colonias americanas, manteniendo su vigencia hasta 1873, en el caso de Puerto Rico, y hasta 1886, en el caso de Cuba.

Una cronología abolicionista tan tardía fue el resultado de la suma de diferentes factores. En el plano de las ideas, sabemos que el movimiento abolicionista español nunca alcanzó el desarrollo y la capacidad de movilización que alcanzaron, por ejemplo, los movimientos abolicionistas británico, francés o norteamericano ${ }^{2}$. Y conocemos también, gracias a un reciente trabajo de Jesús Sanjurjo, las dificultades que tuvieron los abolicionistas españoles para elaborar un corpus doctrinal propio, que no apareciese ante sus iguales como un mero producto importado de la Gran Bretaña $^{3}$. La otra cara de la debilidad del abolicionismo decimonónico español fue, precisamente, la notable fortaleza y la aún más notable capacidad de presión acreditada por aquellos sectores de las élites peninsulares que se organizaron para defender el mantenimiento de la esclavitud en las islas de Cuba y Puerto Rico. Tal como apuntó Cristopher SchmidtNowara, hubo en España una clara coincidencia, tanto doctrinal como estratégica, entre proteccionistas y anti-abolicionistas. Dicho autor establece, de hecho, una relación directa entre la lenta e incompleta transición al capitalismo industrial en España y la vigencia de instituciones aparentemente anacrónicas como el proteccionismo y la esclavitud colonial ${ }^{4}$. En esa línea, el objetivo principal de este trabajo consiste en analizar tanto las ideas que sostuvieron los colectivos pro-esclavistas en la España peninsular como la composición de los mismos. En mi análisis voy a centrarme

\footnotetext{
1 Arroyo, 1992; Schmidt-Nowara, 1999.

2 Schmidt-Nowara, 1999.

3 Sanjurjo, 2018.

4 Schmidt-Nowara, 1999.
} 
en una sola ciudad, Barcelona. No sólo porque el ámbito local permite un mayor nivel de detalle en cualquier tipo de análisis sino porque dicha ciudad era la localidad española que más relaciones acreditaba tener entonces con ambas Antillas, especialmente en el ámbito económico. Podríamos decir, de hecho, que durante todo el siglo XIX y buena parte del siglo XX la capital de Cataluña fue, a la vez, la verdadera capital del colonialismo español $^{5}$. Y que así merece ser estudiada.

Desde el punto de vista cronológico, centraré mi análisis en el estudio de un momento clave de agitación anti-abolicionista, el que se registró tanto en Cuba como en España durante el Trienio Esparterista. Un momento en el que sectores poderosos de la burguesía barcelonesa fueron capaces de organizarse para defender la necesidad de conservar y de proteger la institución de la esclavitud en las Antillas españolas. En su vehemente defensa de la esclavitud llegaron incluso a plantear, de forma implícita, la necesidad de desconocer los tratados de ilegalización de la trata africana que España había firmado con el Reino Unido, en 1817 y en 1835. Una campaña cuyo auge tuvo lugar en 1841 y que se produjo como una reacción defensiva ante la reciente pujanza del movimiento abolicionista internacional, especialmente del británico.

\section{Motivos para la preocupación de los esclavistas en Cuba y en España}

Durante el siglo XIX, los intensos vínculos entre Cuba y España desbordaban el estrecho marco de una relación colonial convencional. No hay que olvidar, tal como señaló William Clarence-Smith, que la isla de Cuba fue, a lo largo de dicha centuria, «probablemente la más rica colonia del mundo» ${ }^{6}$. Siendo así, no resulta en absoluto casual que la primera línea ferroviaria se construyese en dicha Isla (en 1837) antes que en la metrópoli (en España, en 1848). Cabe igualmente tener presente que una buena parte de las élites españolas decimonónicas (a las que mejor cabría denominar élites hispano-antillanas) habían amasado sus fortunas en Cuba o en Puerto Rico. Existe, de hecho, una palabra en castellano, de difícil traducción a otras lenguas, que es «indiano». Un vocablo que se refiere a «una persona que vuelve rica de América». Como veremos, los ricos in-

5 Rodrigo, 2013; Ikunde, 2016.

6 Clarence-Smith, 1971, p. 72. 
dianos (singularmente aquellos que se enriquecieron en Cuba) resultaron tan frecuentes como influyentes en la política y en la sociedad españolas del siglo XIX ${ }^{7}$. La fortuna de buena parte de aquellos ricos e influyentes indianos se había acumulado en el marco de una economía, como la cubana, que gravitaba en torno a las plantaciones de caña de azúcar y que reposaba, por lo tanto, sobre las espaldas de miles y miles de africanos esclavizados $^{8}$. Y aunque la firma de un primer tratado bilateral con Gran Bretaña, en 1817, obligaba a España a acabar completamente con la llegada de nuevos esclavos en sus dominios americanos a partir de 1821, lo cierto es que las necesidades de la economía insular y la demanda de más mano de obra explican por qué el comercio de esclavos se mantuvo en Cuba, pese a su ilegalización, durante casi cincuenta años más, hasta $1867^{9}$.

En aplicación de dicho tratado bilateral, a partir de 1820 se desplazaron a Cuba varios funcionarios británicos cuyo principal cometido era perseguir aquel ilegalizado tráfico de esclavos. Ahora bien, pese a sus esfuerzos y presiones, la ilegalización de la trata no consiguió acabar con las llegadas de africanos esclavizados a dicha Isla, simplemente las convirtió en clandestinas, desplazándolas desde sus principales puertos a otros lugares de su litoral, como playas, cayos, ríos o manglares. Así, en las décadas de 1820 y de 1830 siguieron llegando a Cuba miles y miles de esclavos africanos. Según la TransAtlantic Slave Trade Database, en aquellos veinte años llegaron a la gran Antilla un total de 319.548 cautivos desde África. En dicho período, los esfuerzos de la Armada española por capturar los buques negreros antes de su arribo a las costas de la Isla fueron ciertamente limitados. Entre 1821 y 1840 tan sólo 34 buques fueron «capturados en las costas de la Isla de Cuba» antes de haber podido desembarcar su humana mercancía. Unos buques que llevaban, en su conjunto, 8.875 cautivos a bordo (apenas un 2,7 por 100 de los africanos efectivamente desembarcados en el mismo período $)^{10}$.

Mientras en Cuba se mantenía el comercio de esclavos llevados ilegalmente desde África, a finales de los años 1830 los partidarios de la abolición de la esclavitud seguían alcanzando algunos éxitos, en diferentes espacios. Acabada, por ejemplo, la fase del llamado «aprendizaje», todos

7 Bahamonde y Cayuela, 1992.

8 Moreno, 1978.

9 Franco, 1980; Murray, 1990.

10 Archivo Histórico Nacional [en adelante AHN], Ultramar, Cuba, Gobierno, legajo 3554, exp. 3 . 
los esclavos de todas las West Indies británicas obtuvieron, en 1839, su definitiva libertad. El 3 de diciembre de aquel mismo año, por otro lado, la máxima autoridad de la iglesia católica, el papa Gregorio XVI, publicó un breve pontificio titulado De nigritarum commercio non exercendo con el que condenaba explícitamente el comercio de esclavos ${ }^{11}$. Una bula que sentó muy mal entre las autoridades españolas, tanto civiles como militares e incluso eclesiásticas. Tal como nos recordó en su día Arturo Arnalte, el entonces arzobispo de Santiago de Cuba se negó a publicar dicho breve pontificio en las iglesias de su archidiócesis para no contribuir a poner en peligro la esclavitud en $\mathrm{Cuba}^{12}$.

Meses después de que el obispo de Roma publicara aquella bula, cuyo contenido debería observar obligatoriamente cualquier católico, tuvo lugar en Londres una reunión de la British and Foreign Anti-Slavery Society, un congreso que presionó al ministro británico de asuntos exteriores, el whig Lord Palmerston, para que aumentase la presión ejercida sobre las autoridades españolas. Querían que España acabase definitivamente con el comercio de esclavos y con la esclavitud en sus colonias antillanas. Uno de los resultados de aquel congreso fue que Palmerston acabó nombrando a uno de los más notables líderes abolicionistas británicos, David Turnbull, nuevo Cónsul Británico en La Habana además de Superintendente de Africanos Liberados, un nombramiento que fue recibido con alarmante preocupación por las élites cubanas, como bien describió en su día David Murray $^{13}$. Turnbull llegó a La Habana el 3 de noviembre de 1840 y apenas cuatro días después, el 7 de noviembre, el almirante William Tucker destruía las factorías negreras españolas situadas en la isla de Corisco. Paralelamente, el 19 de noviembre de 1840, el almirante en jefe de la escuadra de la Royal Navy con base en Sierra Leona, Joseph Denman, atacaba y destruía completamente todas las factorías que los negreros hispano-cubanos habían levantado en la desembocadura de los ríos Gallinas, Cestos y Sherbro, cerca de la colonia británica de Sierra Leona. Aquel violento ataque llegó después de un largo bloqueo naval sobre la región de Gallinas, ejercido por la armada británica desde abril de $1840^{14}$.

Hablamos de una serie de acciones que eran a todas luces ilegales según las normas del derecho internacional, pero también de unas acciones

\footnotetext{
11 AHN, Estado, 8037, 1.

12 Arnalte, 1992, p. 65.

13 Murray, 1990, pp. 133-158.

14 García-Cantús, 2004, pp. 229-241.
} 
que sirvieron para infligir importantes daños económicos a los negreros españoles y para mostrar, sobre todo, hasta donde podía llegar la voluntad británica de enfrentarse con quienes practicaban y se beneficiaban del comercio de esclavos hacia Cuba, más allá de los marcos legales acordados con España. Valga, como ejemplo, el caso del súbdito español Miguel Pons, quien fuera arbitrariamente detenido en Corisco, el 7 de noviembre de 1840, y llevado después hasta una cárcel de Londres, donde lo internaron sin ningún tipo de acusación formal. Pese a dicha irregularidad, los británicos retuvieron a Pons durante más de cuatro meses y sólo tras las diplomáticas súplicas de los funcionarios de la embajada española en la capital británica accedieron a liberarlo, el 18 de marzo de $1841^{15}$. La misma presencia, por otro lado, del HMS Romney, un buque de la Royal Navy, artillado con 58 cañones y anclado permanentemente en aguas de la bahía de La Habana desde el verano de 1837, era percibida no sólo como una ofensa sobre la capacidad de España de cumplir y hacer cumplir sus compromisos internacionales sino también como una verdadera afrenta para la soberanía española sobre la isla de $\mathrm{Cuba}^{16}$.

El nombramiento de David Turnbull como Cónsul Británico en La Habana, la paralela destrucción de aquellas factorías negreras ubicadas en las costas africanas y el aumento, en definitiva, de la presión diplomática ejercida por el Foreign Office contra el gobierno español para que acabase definitivamente con el comercio de esclavos y con la institución de la esclavitud, llenó de preocupaciones a los esclavistas cubanos. Unas preocupaciones aún mayores teniendo en cuenta que el espadón Baldomero Espartero era, desde octubre de 1840 el nuevo hombre fuerte de la política española. Algunos de sus adversarios políticos catalogaban al principal líder de la fracción progresista del liberalismo español como «angloayacucho». Se basaban en su doble condición de militar que había participado en (y perdido) las guerras de independencia en la América continental y de político que admiraba el sistema británico. Teniendo en cuenta que la embajada del Reino Unido en España se ubicaba justo enfrente de la residencia oficial de Espartero, en Madrid, se entiende el significado de una pintada que apareció en la fachada del Palacio de Buenavista: «En este palacio habita el regente, pero el que gobierna vive enfrente» ${ }^{17}$. El propio embajador británico Arthur Aston, quien se reunía frecuentemente

\footnotetext{
15 Archivo General de la Administración, Sección 15 África, Fondo 4, 81/7051.

16 Nelson, 2017.

17 Seco, 1969, p. 584.
} 
con Espartero, daba cuenta de la anglofilia del espadón manchego. En una carta que envió a su ministro de Asuntos Exteriores le decía: «Cuanto más reflexiona él, Espartero, sobre este estado de cosas, tanto más convencido está de que la única garantía para la prosperidad e independencia de España es una estrecha alianza con Inglaterra ${ }^{18}$.

En aquel contexto, el nuevo cónsul británico en La Habana, el abolicionista David Turnbull, planteó una idea que desató las alarmas: proponía liberar a todos los africanos esclavizados que hubieran llegado a la isla a partir de 1821, o sea, cuando aquel comercio se había convertido en ilegal. La aceptación de su propuesta significaría una verdadera estocada a la esclavitud en la Isla y provocaría incluso, según algunos hacendados cubanos, el fin de la soberanía española sobre la Isla y su entrada bajo la órbita británica. Fue entonces cuando numerosos potentados cubanos se movilizaron en diferentes sentidos. Tal como señaló José A. Piqueras, «por diferentes razones [la propuesta de Turnbull] era una pretensión inaceptable para propietarios y autoridades: significaba discutir la única fuerza de trabajo disponible e interrumpir de forma efectiva su renovación» ${ }^{19}$. Un grupo de hacendados y comerciantes de Cuba llegó incluso a reunirse con el Secretario de Estado de los Estados Unidos, Daniel Webster, a quien le plantearon la posibilidad de que dicho país se convirtiese en el garante de la esclavitud en Cuba, frente a las ambiciones británicas. Así lo explicaría el propio Webster al embajador español en Washington, Pedro de Alcantara Argáiz: «Me hizo saber que varios hacendados y comerciantes de la Ysla de Cuba, temerosos de que el Gobierno Peninsular los abandonase a la ambición Británica y prefiriendo siempre el pabellón de la Unión al de Ynglaterra, habían renovado sus antiguas proposiciones al gobierno de los Estados Unidos para que la Ysla entrase a formar un nuevo Estado en la Confederación Anglo-Americana, evitándose así su conversión en Colonia Inglesa» ${ }^{20}$.

La suma, de hecho, de todos aquellos factores alimentó el alarmismo de los esclavistas, tanto en Cuba como en España, y les animó a impulsar una rápida campaña (dirigida no tanto a la opinión pública peninsular como, sobre todo, a los miembros del gobierno español) a favor del mantenimiento del statu quo colonial, es decir, de la preservación de la institución de la esclavitud en Cuba y en Puerto Rico.

\footnotetext{
18 Shubert, 2018, p. 262.

19 Piqueras, 1992, p. 275.

${ }_{20}$ Seco, 1968, p. 594.
} 


\section{Los acuerdos de la Junta de Comercio de Cataluña}

El 30 de marzo de 1841 el Tribunal de Comercio de La Habana presentó un informe, tan detallado como beligerante, en defensa de la esclavitud en la gran Antilla. Se trataba de un texto dirigido, en principio, contra los «cuakéros, metodistas y otros sectarios religiosos» a los que acusaban de haber «levantado las sociedades [abolicionistas] que hoy con sus agentes y dinero minan todos los países donde hay esclavitud». Dedicaban sus airadas críticas a todos los británicos avecindados en Cuba («hoy que en cada inglés que desembarca en estas playas puede mirarse un espía y un disfrazado apóstol de esta doctrina») pues consideraban que cualquier ciudadano de aquel país que llegaba a la Isla lo hacía con el «decidido objeto de libertar la raza negra y [...] de arruinar la producción de esta isla». Un tono ciertamente apocalíptico inundaba todo aquel informe: Se afirmaba, por ejemplo, que una conspiración recién descubierta («cuyo estallido debiera haber sido el incendio general de las propiedades y el degüello de todos los blancos») demostraba que Cuba podía convertirse, en cualquier momento, en un nuevo Haití. Y así mismo se afirmaba que los verdaderos organizadores de dichas conspiraciones eran los funcionarios británicos, como Turnbull. El Tribunal de Comercio de La Habana consideraba que si el gobierno español seguía aceptando las presiones abolicionistas ejercidas abiertamente por los gobiernos y por los funcionarios de Su Majestad Británica pronto llegaría la ruina total de la Isla ${ }^{21}$.

Aquel informe llegó a Barcelona a principios de junio de 1841, o sea, apenas tres semanas después de que el anglófilo Baldomero Espartero hubiera jurado su cargo como Regente. Discutió su contenido, en primer lugar, el Tribunal de Comercio de Barcelona, una institución que asumió, sin debate alguno, las propuestas que llegaban desde la capital cubana a sabiendas de que dicha decisión excedía sus atribuciones. Aun así, lo hicieron porque «siendo comerciantes y sobre todo españoles los individuos que la componen» querían evitar «el horroroso porvenir que presentaría a aquellos habitantes la libertad de la gente de color». El Tribunal de Comercio de Barcelona acordó igualmente trasladar la discusión del citado documento a la Junta de Comercio de Cataluña, una institución que era, en palabras de Jordi Maluquer de Motes, «la más importante corporación

${ }^{21}$ Biblioteca de Catalunya, fondo Junta de Comercio [en adelante BC, JC], LX, 3, 56. 
económica de Cataluña, y quizá también de España, en la época» ${ }^{22}$. Dicha Junta de Comercio encargó a su vez, el 7 de junio de 1841, un dictamen a Miguel Biada Buñol, un indiano que se había enriquecido en La Habana antes de regresar a su Cataluña natal. Apenas cinco días después de haber recibido el encargo, Biada presentó un informe basado en una idea principal: la pretendida actitud humanitaria de los británicos con su política abolicionista era una mera pantalla que encubría intereses imperiales. Según decía: «el género de filantropía que tanto proclama [Gran Bretaña] a favor de la esclavitud no se dirije [sic] sino a extinguir los pocos restos que nos quedan de nuestras colonias, en particular a la Isla de Cuba». Afirmaba que el escuadrón de la Royal Navy dedicado a capturar buques mercantes pretendidamente negreros lo que buscaba realmente era expulsar a los veleros de otros pabellones, como el español, del comercio de todo tipo de mercancías en el Atlántico africano y así «hacerse la Señora y única dueña de los frutos coloniales» como «oro, marfil, aceite de palma y otros». Es más, para Biada, el afán británico para liberar a los cautivos que iban a bordo de los buques negreros (los llamados emancipados) no respondía tanto a principios filantrópicos como a necesidades imperiales. Según Biada, «en lugar de devolver los esclavos a sus respectivos países (pues que ciertamente no puede recibir favor mayor el hombre que verse restituido al seno de su patria y familia) lo que hacen es remitir aquellos individuos bien sea a Sierra Leona, cabo de Buena Esperanza o a sus demás colonias del Oeste, que bajo el nombre de aprendices son más esclavos que aquellos por los cuales tanto se interesan ${ }^{23}$.

Miguel Biada defendió entonces la necesidad de mantener en Cuba y en Puerto Rico la institución del trabajo forzado de los africanos y de sus descendientes (o sea, de los esclavos bozales y de los criollos) basándose en su propia trayectoria vital (a partir de «la experiencia que he adquirido en el largo período de 32 años que he habitado las Américas y la mayor parte del tiempo la Isla de Cuba», decía). Afirmaba que dicha experiencia le había «convencido ser imposible pueda cultivarse el territorio entre los trópicos por otros brazos que los africanos o sus descendientes; pues que cuantos europeos e isleños han pasado a aquella zona con el objeto de ocuparse en la agricultura han tenido que desistir de semejante idea por enfermar al dar principio aquellas faenas o quedar inútiles [sic]». Para dar

22 Maluquer de Motes, 1986, p. 317.
23 BC, JC, LX, 3, 71-75. 
más fuerza a sus argumentos, Biada resumía un significativo episodio de la reciente historia de Cuba, que él mismo había vivido en primera persona: la construcción de la primera línea ferroviaria de dicha Isla (y de toda América Latina). Según decía: «El año 1833 el Excmo. Sr. Capitán general Dn. Mariano Ricafort en unión del Superintendente el Excmo. Sr. Don Claudio Martínez de Pinillos se propusieron hacer el camino ferrocarril de la Habana a Güines y al efecto se creó una Junta directiva compuesta del Excmo. Sr. Conde de Fernandina, el Excmo. Sr. Dn. Joaquín Gómez y el esponente [sic], por medio de accionistas [...]. Al efecto se invitaron trabajadores europeos y anglo americanos y efectivamente llegaron con aquel objeto un gran número de alemanes, suizos, irlandeses y angloamericanos con isleños de Canarias quienes dieron principio al trabajo, sin poder seguir en él los más, el muy corto período de seis meses, en fuerza de los estragos de la enfermedad ocasionada por las fatigas y cansancio que produce aquel clima abrasador». Si España no quería arruinar la prosperidad económica de Cuba debía, por lo tanto, mantener la esclavitud africana en la Isla, enfrentándose directamente a las presiones de un Reino Unido tan hipócrita como egoísta: «La Inglaterra, señores, ahora y en todos tiempos no ha procurado más que su bienestar», consignaba entonces Biada, quien asimismo denunciaba «aquel insaciable egoísmo de que [Gran Bretaña] en todos tiempos ha dado tan repetidas pruebas, hacerse la Señora y única dueña de los frutos coloniales» ${ }^{24}$.

Además de aquel primer dictamen sobre la cuestión de la esclavitud en Cuba, realizado por Miguel Biada, hubo un segundo informe, elaborado también a requerimiento de la Junta de Comercio de Cataluña por una comisión de siete empresarios de la capital catalana nombrados a tal efecto. Un informe elaborado por siete comerciantes que compartían un rasgo vital común: los siete se habían enriquecido previamente en Cuba, donde alguno todavía conservaba intereses y negocios. Se trataba de Jaime Badia Padrines, Juan Illas Ferrer, Hilarión Azcárate, Jaime Torrents Serramalera, Francisco Prats, Jaime Taulina Villalonga y del propio Miguel Biada Buñol. El criterio de selección de aquellos siete ponentes se basaba en una sencilla idea. Según decía la Junta de Comercio: «Se creyó oportuno oír a personas que por una larga permanencia en aquel país han adquirido conocimientos teóricos y prácticos en el asunto». Aquel dictamen colectivo elaborado por aquellos siete indianos de Barcelona no sólo

\footnotetext{
24 Ibidem.
} 
hacía suyas las ideas recogidas en el informe del Tribunal de Comercio de La Habana sino que iba incluso más allá. Daban cuenta de su voluntad de impedir que el español Congreso de los Diputados llegase a debatir sobre la necesidad de mantener o de acabar con la esclavitud en las colonias antillanas. Hablaban, de hecho, del «temor de que nuestro Congreso se empeñe inconsideradamente en la cuestión de esclavitud y en realidad si esto aconteciese la sola discusión sería una señal de terrible alarma para nuestras posesiones ultramarinas, porque aquellos habitantes recelosos de la inexperiencia y ardimiento declamatorio que acompaña generalmente semejantes debates, verían en ellos el origen de una lucha estemporánea [sic] pero que pasmaría el espíritu de empresa y la confianza se extinguiría en aquellos países, hasta el punto de provocar la emigración de los blancos con sus capitales $»^{25}$.

Aquella comisión sugirió a la Junta de Comercio de Cataluña que hiciera suyas todas las peticiones del Tribunal de Comercio de La Habana, exigiendo una firme actitud del gobierno español frente a las injerencias de los británicos, en general, y de David Turnbull, en particular: «Nosotros invocaremos con toda la energía que merece la gravedad de este negocio el apoyo de la Junta de Comercio para que represente al Supremo Gobierno a fin de contener estas invasiones extranjeras con grave peligro de la soberanía de la metrópoli. Este es el pretesto [sic] con que la poderosa Albión quiere infiltrarse, por decirlo así, en todas las cuestiones futuras que puedan ocurrir sobre la libertad de los esclavos y si no se corta de raíz semejante abuso, plantamos desde ahora un semillero de discordias y de compromisos en nuestras colonias». Aquellos siete indianos catalanes iban incluso más allá que sus colegas habaneros pues proponían la necesidad de «disolver la comisión mixta que existe en la Habana con dos vocales ingleses (...) y por este medio remediaranse tal vez las faltas que se cometieron por el Gobierno absoluto en el tratado de $1817 \gg^{26}$. Vale la pena resaltar que los argumentos que utilizaron los hombres de la Junta de Comercio de Cataluña eran propia y plenamente liberales: cuestionaban veladamente la legitimidad del tratado hispano-británico de ilegalización del comercio de esclavos acordado en 1817 en la medida que había sido firmado por el gobierno de un rey absolutista, y afirmaban que el abolicionismo militante de los británicos chocaba con un bien superior, con el

25 BC, JC, LX, 3, 68.

${ }^{26}$ Ibidem. 
sacrosanto derecho de la propiedad (en este caso, de la propiedad de los esclavos). Así lo había hecho explícitamente en su informe Miguel Biada, llevando a colación debates similares registrados en los Estados Unidos, unos debates que él había podido vivir en primera persona: «Hallándome en el Capitolio de Washington [decía Biada] tuve ocasión de presenciar un debate sobre la cuestión de emancipación y el orador representante de los Estados del Sur después de haber defendido su opinión con todo aquel interés y energía a que era impelido preguntó ¿en qué se apoyaba ese derecho con que se creía investida la Inglaterra para disponer de los sagrados derechos de propiedades individuales?» ${ }^{27}$.

Otro de los argumentos esgrimidos entonces por la Junta de Comercio de Cataluña en su defensa de la esclavitud en Cuba y Puerto Rico era el carácter benigno que dicha institución había tenido siempre en los dominios españoles y, singularmente, la posibilidad de que los esclavos pudiesen obtener su libertad gracias a prácticas e instituciones legales como la manumisión y la coartación ${ }^{28}$. Hablaban, de hecho, de diferentes «ejemplos de humanidad para la fácil manumisión de nuestros siervos». Así, frente a la pretendida superioridad moral de los abolicionistas británicos, los esclavistas españoles defendían otro tipo de superioridad moral basada en una pretendida armonía de razas entre españoles y africanos. Afirmaban también que «el encono de la raza Anglo-Sajona contra la Africana jamás ha sido conocido por los Españoles» añadiendo: «Bien podemos decir que los españoles en siglos de menos libertad y menos civilización hemos sabido darles ejemplos [a los británicos] para la fácil manumisión de nuestros siervos». Siendo así, concluían: «Que nos dejen solos los estrangeros y nos arreglaremos a la Española, sin necesidad de sus consejos ni de sus ejemplos [...]. Queremos salvar con tiempo la independencia de nuestra administración colonial y el derecho inconcuso de lavar nuestra ropa en nuestra propia casa sin los riesgos y compromisos que nos traería la ignorancia presuntuosa de los estraños sobre nuestros hábitos y costumbres y más que todo sobre la índole generosa, por más que se diga, de toda la raza Española en ambos mundos $[$ sic $] \gg^{29}$.

Cabe señalar, por último, un argumento que se sumaba a los anteriores, al que probablemente debemos otorgar la mayor importancia. Y

\footnotetext{
27 BC, JC, LX, 3, 71-75.

${ }^{28}$ Lucena, 1999.

29 BC, JC, LX, 3, 68.
} 
es que para los empresarios que firmaron aquel dictamen pesaban, por encima de cuestiones ideológicas o políticas, la defensa de los numerosos intereses económicos españoles radicados en Puerto Rico y, sobre todo, en Cuba. Precisamente debido al notable peso de dichos intereses, había que evitar cualquier discusión que alterase el statu quo vigente en Cuba y en Puerto Rico. Según sus propias palabras: «La masa de intereses que existen entre la Península y sus colonias es de tal importancia y magnitud que sería preciso renunciar a todos los principios de buen gobierno para despeñarnos inconsideradamente por semejantes precipicios». Así se entiende mejor porqué la Junta de Comercio de Cataluña hizo suyas, punto por punto, todas las propuestas elaboradas por la citada comisión, la cual había decidido, a su vez, asumir por entero el informe elaborado tres meses antes por la institución que agrupaba a los comerciantes habaneros. Dicha institución catalana acordó finalmente «dirigirse al Gobierno en apoyo de cuanto expone el Tribunal de Comercio de La Habana». Sus dirigentes afirmaban que ignorar dichas propuestas o mirar hacia otro lado «no podría menos que causar grandes perjuicios a todo el comercio general de la península» ${ }^{30}$. Y así lo hicieron constar, el 22 de junio de 1841, mediante una carta remitida al regente Espartero.

Unos meses después, en noviembre, el mismo asunto volvió a someterse a debate público. La Junta de Comercio de Cataluña nombró entonces una segunda comisión, compuesta también por siete miembros, encargados de elaborar un segundo dictamen. Cinco de aquellos individuos (Jaime Badia Padrines, Jaime Torrents Serramalera, Jaime Taulina Villalonga, Francisco Viñas y Juan Illas Ferrer) habían formado parte de la primera comisión mientras que los otros dos (José Xifré Casas y Valentín Martínez) se incorporaron entonces ex novo. Aquel segundo dictamen respondía directamente a la propuesta elaborada por David Turnbull en su calidad de Superintendente de Africanos Liberados relativa a la necesidad de crear un nuevo tribunal mixto hispano-británico, con sede en La Habana, que pudiese dar la libertad a todos aquellos esclavos que hubieran llegado a la isla en fecha posterior a octubre de 1820. La idea de Turnbull era sencilla: Si a partir de aquella fecha el comercio de esclavos había pasado a ser ilegal en Cuba y en Puerto Rico todos aquellos africanos que hubieran llegado a ambas islas desde en-

30 Ibidem. 
tonces deberían ser declarados inmediatamente libres, tras la preceptiva sentencia de aquel nuevo tribunal.

Aquel segundo dictamen, elaborado en noviembre de 1841, nuevamente por encargo de la Junta de Comercio de Cataluña, volvía a insistir en la absoluta temeridad que significaría abrir el melón de la discusión sobre la abolición de la esclavitud en las colonias españolas: «La sola discusión sería una señal terrible de alarma para nuestras posesiones ultramarinas», decían. Las razones aducidas eran varias y todas apuntaban en el mismo sentido: (1) «Si el gobierno absoluto del año diez y siete no tuvo siquiera la dignidad de condenar el comercio africano con independencia y orgullo español ¿debe el gobierno representativo de 1841 consultar su propia humillación, admitiendo con sobrada cortesía propuestas tan injustas como irritantes?»; (2) «no se ha tomado en cuenta por el Ministerio la extremada susceptibilidad de aquellos pueblos en materias de esclavitud»; (y 3 ) «cartas tenemos en Barcelona de personas respetables de la Isla de Cuba anunciando que algunos vecinos de aquella Isla ofrecen en venta sus propiedades por la mitad de su valor intrínseco, sin más motivo que la consulta que nuestro Ministerio ha verificado». Según concluían, las autoridades españolas debían enfrentarse directamente a las pretensiones abolicionistas impulsadas por los británicos si no querían arruinar sus colonias antillanas. Tal como hicieran en la primavera de 1841, también en el otoño de aquel año la Junta de Comercio de Cataluña decidió asumir las conclusiones de aquella segunda comisión, elevándolas a la superioridad. Al hacerlo, lo argumentaron también en clave de intereses domésticos, propiamente catalanes, pues consideraban que los resultados de tal discusión «podrían influir muy directamente en la pérdida de cuantiosos intereses y en la miseria de un gran número de familias, tanto de este como de aquel país, que tienen radicadas sus fortunas en la Isla de Cuba» ${ }^{31}$. Aquella actitud, de hecho, de la Junta de Comercio confirma las apreciaciones apuntadas hace años por Josep Maria Fradera, quien destacó, para esta misma coyuntura, «la negativa rotunda de la burguesía catalana a la menor reforma en el régimen político de las Antillas» y la justificación sistemática del comercio de esclavos y de la esclavitud, en $\mathrm{Cuba}^{32}$.

${ }^{31}$ Representaciones de la Junta de Comercio de Cataluña e informes que acompañó relativamente al proyecto que ha propuesto el gobierno inglés de emancipación de esclavos en las colonias españolas, Barcelona, Imprenta de los herederos de Roca, 1841.

32 Fradera, 1987, pp. 261-262. 


\section{La Junta de Comercio de Madrid}

La Junta de Comercio de Cataluña no sólo hizo suyos los dos dictámenes elaborados, en junio y en noviembre, por aquellas dos comisiones de indianos enriquecidos en las Antillas sino que acordó «comunicar de oficio a cada uno de los Diputados del Principado [de Cataluña] un ejemplar impreso de estos documentos» así como dirigirse igualmente «a las demás Juntas de Comercio de la península interesándolas para que representen al supremo gobierno en el sentido que quiere hacerlo la de Barcelona». En diciembre de 1841 publicaron a tal efecto un interesante folleto que hicieron circular por toda España. Diríamos que la Junta de Comercio de Cataluña quiso adoptar entonces el papel de abanderada de la lucha anti-abolicionista y pro-esclavista en la España peninsular, recogiendo el testigo planteado aquel mismo año por el Tribunal de Comercio de La Habana.

No cabe duda de que sus esfuerzos tuvieron cierto éxito. La propia Junta de Comercio de Madrid decidió discutir entonces, en su reunión del 4 de enero de 1842 , la susodicha cuestión. Lo hizo, precisamente, «penetrada [...] del grande interés de la comunicación impresa hecha por la de Cataluña [y] de sus exposiciones al gobierno de la Reina sobre el importante punto de la emancipación de los negros esclavos de las Islas de Cuba y Puerto Rico». La madrileña Junta de Comercio encargó a uno de sus vocales, el aragonés Lorenzo Calvo Mateo, que elaborase un informe sobre dicha materia. El tal Lorenzo Calvo era un empresario de ideología profundamente liberal (implicado en la fracasada conspiración de Torrijos, por ejemplo), quien se había enriquecido, por más señas, en el contexto del imperio español, aunque en su caso no en el marco de las Antillas españolas sino en el sur de Asia (como factor en Cantón, primero, de la Real Compañía de Filipinas y como hombre de negocios particular, después, tanto en Cantón como en Manila) ${ }^{33}$.

El 28 de febrero de 1842 la Junta de Comercio de Madrid asumió completamente el informe propuesto por Calvo. Hizo suyo un dictamen dedicado a defender sin rubor la bondad de la esclavitud en las colonias españolas. Un informe en el que su autor se preguntaba, por ejemplo: «¿Quién puede dudar que los negros esclavos de nuestras Antillas en su estado de esclavitud son más felices que los negros emancipados de la Jamaica o los libertos de las Islas de Cuba y Puerto Rico?»; y en el que su

33 Fradera, 1999; Permanyer, 2013. 
mismo autor respondía: «Pensar que la ventura y felicidad que gozan los esclavos de nuestras Antillas habrá de mejorar con la pretendida emancipación, es una quimera que solo puede alimentarse en el mal entendido celo y delirante fanatismo de los abolicionistas». Los argumentos usados por Lorenzo Calvo y dados por buenos por la Junta de Comercio de Madrid coincidían, en buena medida, con las ideas defendidas meses antes por sus homólogos de Barcelona, aunque otorgaba un mayor peso a las cuestiones estrictamente económicas.

Para la institución madrileña: (1) la emancipación de los esclavos en las dos Antillas españolas provocaría una nueva y sangrienta revolución, similar a la registrada en Haití (hablaban literalmente de «las trágicas escenas de sangre y horror en que se vio envuelta la Isla de Haite [sic] desde el momento en que los negros se constituyeron en estado de libertad, escenas de muerte, de terror, de ruina que se repetirían sin duda en las Islas de Cuba y Puerto Rico si se llevase a cabo la emancipación de los esclavos» y se preguntaban, a modo de interrogación retórica, «¿quién duda que aquellas islas serían el teatro de la destrucción del país y que el degüello de los blancos, la violencia y el estupro sería el primer fruto de la fatal condescendencia del gobierno español con las pretensiones egoístas, simuladas e interesadas del gobierno inglés?»); (2) la economía de ambas islas entraría en una profunda e irremediable crisis productiva que las llevaría pronto a la ruina más profunda y absoluta (apuntaban que «no se trata[ba] solo de una cuestión filantrópica, sino de una cuestión de vida y muerte para la agricultura, para la industria y para el comercio general de la península y de aquellas Islas»); (3) recordaban que España no tenía recursos suficientes para indemnizar, como debiera verificar si aprobaba la emancipación de los esclavos de Cuba y Puerto Rico, a los propietarios de aquellos centenares de miles de esclavos que había en ambas islas; (4) alertaban de que los negocios e intereses de muchos comerciantes e industriales peninsulares se resentirían notablemente si se aceptaba acabar con la esclavitud en ambas Antillas, con el consiguiente perjuicio a la economía española, en su conjunto (según sus palabras: «Horroriza la idea de los inmensos perjuicios que irrogaría a los productores españoles de aquellas Islas y de la península si llegara a darse el fatal decreto de la emancipación; porque por él desaparecerían doscientos millones [de reales] que saca anualmente el comercio español de las citadas Islas. Por él quedarían estancados los granos de Castilla, porque les faltaría el desagüe de más de cien mil barriles de harina que se exportan anualmente para aquellos habitantes. Por él se perderían por falta de salida los aceites, vinos y aguar- 
dientes de las bodegas de Andalucía y Cataluña. Por él quedaría la península privada del mercado de Cuba y Puerto Rico, y por consecuencia necesaria paralizada la industria gallega y catalana en los tejidos de lino y algodón»...); (y 5 y último) la Hacienda española dejaría de ingresar los cuantiosos sobrantes de Ultramar, o sea, los voluminosos superávits de la hacienda cubana, y también puertorriqueña, con el consiguiente perjuicio a los contribuyentes peninsulares (se preguntaban, de hecho, «¿De qué modo se supliría la entrada en el Tesoro público de unos cien millones [de reales] que de aquellas islas vienen todos los años a reforzar las Cajas públicas de la Península?») ${ }^{34}$.

Aquellos argumentos expuestos por la Junta de Comercio de Madrid expresan muy bien las razones concretas con las que dicha institución llenaba de contenido su defensa de la esclavitud en las Antillas españolas. No hay que olvidar, por otro lado, que no hubo ninguna ley que decretase la abolición de la esclavitud en la España peninsular, y que hubo personas esclavizadas en España hasta la década de 1830 en algunas ciudades de la península, como por ejemplo en Cádiz, tal como nos han recordado recientemente Arturo Morgado y Eloy Martín Corrales ${ }^{35}$. Tanto para Lorenzo Calvo como para sus colegas de las Juntas de Comercio de Madrid y de Cataluña, la institución de la esclavitud había estado presente hasta unos pocos años antes de que hubieran discutido y aprobado sus respectivos manifiestos.

También en Barcelona y en aquellos primeros años 1840 se consolidó un pequeño núcleo de activistas antiesclavistas, bien estudiado por Albert Garcia Balañà. Dicho autor señala que la principal característica de aquel grupo era, precisamente, su debilidad. De todos aquellos activistas, el más dinámico era el impresor y editor Francisco Bergnes de las Casas, quien se sirvió de su revista mensual El Museo de Familias para publicar varias traducciones al castellano de otros tantos textos abolicionistas ${ }^{36}$. El catalán Bergnes utilizó asimismo su barcelonesa imprenta para difundir textos escritos por activistas abolicionistas británicos como, por ejemplo, J. G. Alexander (y sus Observaciones sobre la esclavitud y comercio de esclavos) y Richard Madden (y su Informe sobre la esclavitud en la Isla de $(u b a)$, ambas publicadas en un mismo folleto, editado por él en 1841.

${ }^{34}$ Colección de varios documentos del expediente que existe en la Junta de Comercio de esta capital referente al proyecto de emancipación de los esclavos negros de las Antillas Españolas, Madrid, Imprenta Nacional, 1842.

35 Morgado, 2018, y Martín, 2018.

36 García Balañà, 2013. 
Parece bastante claro que, al menos en aquel año y en el siguiente, hubo en Barcelona una cierta confrontación de ideas entre detractores y defensores de la esclavitud. Un debate que se aprecia repasando la prensa de la ciudad. Si un activista antiesclavista como Bergnes utilizó su revista El Museo de las Familias como altavoz de sus ideas, diferentes diarios de Barcelona publicaron o reprodujeron notas con argumentos similares a los defendidos por la Junta de Comercio de Cataluña, usando un tono igualmente apocalíptico. Un periódico titulado significativamente el Liberal Barcelonés publicó, en abril de 1842, «ciertos documentos, los cuales demuestran a su vez que la Inglaterra está urdiendo una horrible trama para entregar nuestras Antillas a la revolución más espantosa por el medio traidor de la Emancipación de los negros; plan dirigido a ser ver a que se perpetre una conmoción general en la isla de Cuba y sea la clase la que figure en la sangrienta escena». Dicho periódico acusaba precisamente a los británicos de que sólo querían «completar nuestra ruina, privándonos de la única colonia rica que nos queda, introduciendo en ella la emancipación de los esclavos, para que perezcan los ingenios, quede arruinado el comercio de ambos hemisferios y sean además víctimas de la saña negrera los habitantes blancos» ${ }^{37}$. También las páginas del Diario de Barcelona publicaron notas y noticias, de todo tipo, que lo mismo destacaban la hipocresía británica en materia de esclavitud como lamentaban las pérdidas económicas que los británicos habían infligido a los negreros de Gallinas con la destrucción de sus factorías ${ }^{38}$. Cabe concluir que, aun salvando ciertas distancias, pueden encontrarse notables similitudes entre Barcelona y Madrid, por un lado, y Río de Janeiro, por otro, en atención a la similar capacidad de sus élites pro-esclavistas de conseguir que sectores de la prensa local (o sea, de la opinión publicada), asumiesen y difundiesen sus postulados $^{39}$.

\section{La burguesía indiana de Barcelona, defensora del esclavismo en Cuba y Puerto Rico}

En aquel desigual debate entre pro-esclavistas y abolicionistas de Barcelona, tanto la riqueza personal y la proyección pública como la capaci-

\footnotetext{
37 Diario de Barcelona, 30.04.1842, pp. 1652-1653.

38 Diario de Barcelona, 02.04.1841, p. 1462, y 24.10.1842, p. 4059.

39 Para el caso de Río de Janeiro, véase El Youssef, 2010.
} 
dad de presión y la cercanía al poder de los primeros parecen haber sido notablemente superiores a las que llegaron a alcanzar los segundos. Vale la pena, en este sentido, repasar brevemente la trayectoria vital de algunos de los indianos que habían elaborado y firmado aquellos dos dictámenes aprobados después unánimemente por la Junta de Comercio de Cataluña. Voy a resumir así las trayectorias vitales de cinco de los firmantes de aquellos dos manifiestos de 1841, o sea, de «los tres Jaimes» (Badia, Torrents y Taulina) así como de José Xifré y de Miguel Biada, empezando precisamente por este último. Apenas unas pinceladas biográficas para mostrar no sólo hasta qué punto algunos de aquellos individuos que actuaron en nombre de la catalana Junta de Comercio estuvieron directa y personalmente vinculados con el fenómeno del tráfico ilegal de esclavos y de la esclavitud, en las Antillas españolas, sino que todos formaron parte (por méritos propios y gracias a la reinversión en Cataluña de sus caudales, acumulados en su previa etapa americana) de la alta burguesía catalana.

Nacido en Mataró, en 1789, Miguel Biada Buñol había emigrado joven a América. Se instaló primero en Maracaibo donde ejerció como comerciante durante trece años, entre 1808 y 1821 , y cuando aquella portuaria ciudad venezolana cayó en manos de las tropas bolivarianas, Biada la abandonó para instalarse en La Habana. Allí residió hasta su definitivo regreso a Cataluña, en 1840. En aquellos diecinueve años en la capital cubana Biada ejerció como uno de los más destacados comerciantes de dicha ciudad, llegando a participar en la famosa camarilla del Capitán General Miguel Tacón (1834-1837), con quien acabó tejiendo una relación bastante cercana. Al regresar a Barcelona, en 1840, el capital social de su empresa habanera Biada y Cía. era de 173.000 pesos fuertes (de los cuales 100.000 correspondían a su capital comanditario). Dicha compañía se dedicaba de manera preferente al comercio marítimo y disponía de una flota de varios buques para cruzar el Atlántico ${ }^{40}$. A través de dichos barcos Miguel Biada participó también en el tráfico ilegal de africanos esclavizados hacia Cuba. En varios casos fue su cuñado, el capitán mercante Gaspar Prats, el responsable de las expediciones a las costas de África armadas desde La Habana. Así sucedió, por ejemplo, con un viaje de la goleta Barbarita (en 1830), con otro del bergantín Andaluz (en 1834) y con un tercer viaje, del bergantín San Pedro (a) Marinero (en 1836) ${ }^{41}$. Cabe añadir

40 Cusachs, 2007.

41 AHN, Estado, legajo 8022, documento 36 (2). Transatlántic Slave Trade Database (slavevoyages.org) \# 970, 1359 y 1459. 
que la firma Preciós Viada y Cía. de Santiago de Cuba, participada por su hermano Onofre Viada Buñol, estuvo también vinculada a la trata ilegal, a menudo en expediciones armadas desde La Habana por el portugués Joaquín José Pereira D'Abreo, como la que tuvo lugar en 1838 en el bergantín de bandera portuguesa Dois Amigos ${ }^{42}$.

Instalado en Mataró, en 1840, Miguel Biada se dedicó a impulsar diferentes proyectos empresariales, sin abandonar sus intereses en La Habana, confiados a su sobrino Onofre Viada Balanzó y a su primogénito Miguel Biada Prats. El más destacado de todos aquellos proyectos fue el impulso de la primera línea ferroviaria de la España peninsular, la que acabaría uniendo la ciudad natal de los Biada (Mataró) con Barcelona. Miguel Biada fue uno de los miembros de la primera Junta Directiva (o Consejo de Administración) de la sociedad del Camino de Hierro de Barcelona a Mataró. Ejerció como tal desde su constitución, en julio de 1844, hasta su muerte, en abril 1848, asumiendo en aquel tiempo el cargo de Tesorero de la compañía. Las oficinas de dicha empresa se establecieron, precisamente, en el mismo lugar donde estaba su despacho, en Barcelona, en los llamados Pórticos de Xifré43.

Otro indiano que se había enriquecido, como Biada, también en La Habana gracias sobre todo a su participación en el comercio marítimo fue Jaime Torrents Serramalera, cuya trayectoria vital ha sido resumida recientemente por Xavier Juncosa ${ }^{44}$. Sabemos que Torrents había tenido, como Biada, cierta participación en el comercio ilegal de esclavos con destino a Cuba. Financió, en su caso, al menos cinco expediciones negreras habilitadas, entre 1828 y 1838, en sus buques Emprendedor, Diógenes y La Primera de Cataluña. Tras su etapa cubana Torrents se instaló en Barcelona, en 1838, comprando el prestigioso palacio Savasona, en la calle Canuda, desde donde siguió gestionando su amplia flota de veleros mercantes. Al fallecer, en 1854, tenía invertido capital en cuatro fragatas (Diógenes, Adonis, Primera de Cataluña y Julia), en tres bergantines (Joaquín, Emprendedor y Amnistía) y en una polacra-goleta (Eulalia).

${ }^{42}$ House of Commons Parliamentary Papers, Slave Trade, Class A, Correspondence with the British Commissioners at Sierra Leone, The Havana, Rio de Janeiro, and Surinam, relating to Slave Trade. From June 30th to December 31st 1839, London 1840: «Report of the Case of the Brig "Dous amigos", Fernando Jozé Carreira, Master».

${ }^{43}$ Cusachs, 2007, p. 61.

44 Juncosa, 2017. En su trabajo, dicho autor analiza también el contenido doctrinal de los documentos generados por la Junta de Comercio de Cataluña, los cuales analizo en este artículo. 
Había mandado construir, además, otras dos polacras y había invertido también fondos en sendas empresas navieras catalanas: en la Línea de Vapores Hispano-Inglesa, impulsada por Pablo María Tintoré, y en la firma Bofill y Martorell, cuyos vapores cubrían la ruta entre Cádiz y Marsella. Torrents fue uno de los comerciantes más ricos de su generación: Al fallecer, en 1854, la fortuna que dejó a sus herederos superó los 2,5 millones de pesetas ${ }^{45}$.

Otro de los firmantes de aquellos manifiestos anti-abolicionistas de 1841 fue Jaime Taulina Vilallonga, un comerciante y naviero que se había enriquecido igualmente gracias al comercio marítimo durante sus años de residencia en La Habana. En abril de 1839 Taulina fundó en La Habana la firma Taulina y Romagosa. Pronto dejó a su socio, Francisco Romagosa Raventós, al frente de sus negocios en Cuba y se instaló en Barcelona, donde desarrolló una notable actividad empresarial. Giró, de hecho, bajo su nombre propio hasta que se retiró, en 1864, de la cotidiana gestión de sus negocios en Barcelona, los cuales dejó al cargo de su hijo Jaime Taulina Garriga y de su yerno Buenaventura Conill Parés, gerentes de la casa Hijos de Taulina ${ }^{46}$. Entre las relaciones tejidas, en Cuba, por Taulina y que conservó durante toda su vida quiero destacar la de uno de los empresarios más ricos e influyentes de la Isla, me refiero al negrero alavés Julián Zulueta Amondo. Así, en 1866 y tras el fallecimiento tanto de su primer suegro, Jaime Samá Martí, como de su cuñado José Samá Mota, Zulueta acudió precisamente a Taulina a quien le pidió un «favor especial» basándose «en nuestra antigua amistad». Le rogó que representase el interés de sus cuatro hijos Zulueta-Samá frente a los de su jovencísimo sobrino, Salvador Samá Torrents, segundo marqués de Marianao, en cuestiones hereditarias ${ }^{47}$.

Como en el caso de Miguel Biada, tampoco el inventario post-mortem del indiano Jaime Taulina Vilallonga ofrece una valoración económica del monto total de su fortuna. Aun así no hay duda de que fue cuantiosa. Solamente el valor de su participación en la casa de comercio Hijos de Taulina (sumando su capital en dicha empresa, el saldo a su favor en su cuenta corriente y además el efectivo en caja) más el valor de diferentes pagarés firmados a su favor sumaba 793.694 pesetas. A dicha cifra cabría sumar, ade-

45 Ibidem.

46 Arxiu Històric de Protocols Notarials de Barcelona [en adelante AHPB], Fernando Moragas Ubach, manual de 1863, tercera parte, fols. 2263-2265, 29.12.1863.

47 Arxiu Municipal de Lloret de Mar, fondo patrimonial Taulina, 502-001-123. 
más, el valor de sus acciones y obligaciones así como de sus numerosas fincas rústicas y urbanas, sobre todo del palacete que Taulina se había hecho construir en la céntrica calle de la Merced, números 20, 22 y $24^{48}$.

Otro de los firmantes de aquellos manifiestos fue Jaime Badia Padrinas, quien había nacido en Torredembarra, en 1796, y emigrado a Matanzas (Cuba) en 1812, reclamado por su tío Esteban Badia, a quien ayudó en la gestión de su casa de comercio. Cuando éste falleció, en 1818, Jaime Badia se situó al frente de los citados negocios aunque, dada su condición de menor de edad, necesitó el apoyo y el concurso legal del también catalán Tomás Gener Bohigas (1787-1835), a quien cabe considerar como principal líder ideológico del denominado «grupo liberal de Matanzas». Tomás Gener fue elegido Diputado por La Habana en las cortes del Trienio Liberal y a él le correspondió, por cierto, firmar el decreto de destitución de Fernando VII, dado el apoyo del monarca a la invasión de los Cien Mil Hijos de San Luis. Mientras tanto, Jaime Badia siguió con la gestión de su casa de comercio en Matanzas, configurada bajo la razón social de Badia y Hermano al poco de haber alcanzado su mayoría de edad. No acabó regresando a Cataluña hasta 1840, tras haber pasado una breve temporada en los Estados Unidos.

Cabe señalar que tanto Jaime Badia como algunos de sus familiares más cercanos participaron también en el comercio de esclavos, especialmente en los últimos años de su fase legal. Su tío y padrino de bautismo, Mariano Flaquer Lluch, fue uno de los negreros que operaron en Barcelona, desde cuyo puerto habilitó, cuando menos, las expediciones del bergantín Santa Rosalía (en 1817) y de la fragata Nuestra Señora de la Merced (en 1820), y desde donde contribuyó a financiar diversas expediciones organizadas por otros comerciantes negreros de la ciudad (como la del bergantín San José, en 1817). El propio Jaime Badia Padrines reconoció haber despachado, en Matanzas y en 1819, «una goleta para el comercio o trata de esclavos en la Costa de África», lamentándose años después de «que al llegar al puerto de la trata y con el cargamento ajustado fue apresado por un buque de los Estados Unidos de América», que la llevó después hasta Nueva York ${ }^{49}$. Al poco de su regreso a Cataluña, Badia emprendió una notable carrera política y empresarial que le llevó a ser dipu-

48 AHPB, Fernando Moragas Ubach, manual de 1872, segunda parte, 09.07.1872, fols. 709-720.

49 Arxiu Històric de Tarragona, Protocolos Notariales, Vicente Fontanilles, manual de 1852, 23.01.1852, fols. 28-29. 
tado en las Cortes españolas, en varias legislaturas, además de primer Administrador del recién creado Banco de Barcelona. Invirtió también sus capitales en otras empresas catalanas como la Maquinista Terrestre y Marítima, la España Industrial o la Aseguradora ${ }^{50}$.

Mayor aún que la fortuna acumulada por Jaime Badia fue la de José Xifré Casas, un rico hombre de negocios que había vivido en La Habana hasta 1823, fecha en que trasladó su residencia a Nueva York. Allí compartió negocios con el empresario norteamericano de origen gallego Peter Harmony (o Pedro Ximeno García), uno de los principales negreros de Manhattan. En Cuba, la principal fuente de actividad de Xifré parece haber sido la administración de una tenería, cuya propiedad conservó durante toda su vida. No regresó, sin embargo, a Europa hasta 1830, sumando cincuenta y dos años. Pasó entonces a vivir con su joven esposa entre Barcelona y París, invirtiendo buena parte de sus capitales en la compra o construcción de diversas fincas urbanas, sobre todo en Barcelona. Y aunque no conocemos cual era el valor de su patrimonio, al morir, sabemos que la fortuna que dejó su único hijo, el cual falleció sólo doce años después que su padre, se valoró en 4.353 .306 pesetas $^{51}$. Tiene sentido, por lo tanto, un dicho popular que se decía en la Barcelona del siglo XIX: «es más rico que Xifré» 52 .

No cabe duda, en definitiva, de que los defensores de la esclavitud en Barcelona se encontraban entre los hombres de negocios más ricos de la ciudad. Así lo muestran los casos de Jaime Badia, de Jaime Taulina, de Jaime Torrents, de Miguel Biada o de José Xifré. Tampoco cabe duda de que sus propuestas fueron asumidas por sus iguales, es decir, por sus colegas asimismo integrantes de la burguesía mercantil e industrial de la capital catalana. Junto a sus homólogos madrileños y habaneros, aquellos grandes empresarios barceloneses que trabajaron para defender la esclavitud en Cuba acabaron consiguiendo, de hecho, sus objetivos. Una de las peticiones concretas que la Junta de Comercio de Madrid elevó el 2 de marzo de 1842 al gobierno español era muy clara. Le decían: «Exija del gobierno inglés que retire el Cónsul que actualmente tiene en la Habana [o sea, David Turnbull], por ser su presencia muy perjudicial a la pública tranquilidad de aquella Isla». Lo cierto es que Turnbull se había conver-

50 Blasco, 2009.

51 Archivo Histórico de Protocolos Notariales de Madrid, Miguel Castillo Alva, manual de 1872, primera parte, protocolo 31484, fols. 77-378.

52 Ramón de San Pedro, 2017; Yashima, 2017. 
tido en un personaje molesto, incluso para los propios británicos que vivían en Cuba. El cese del whig Lord Palmerston y su substitución por el tory Earl of Aberdeen como responsable principal de la diplomacia británica, privaron al abolicionista Turnbull de su principal apoyo en el Foreign Office. Así, temiendo por su vida David Turnbull pasó a alojarse, en junio de 1842, en el Romney, un crucero de la Royal Navy que estaba anclado en La Habana desde hacía casi cinco años ${ }^{53}$. Y dos meses después, en agosto de 1842, Turnbull abandonó definitivamente Cuba para dirigirse a Las Bahamas sin haber cumplido ninguno de sus objetivos.

La ulterior defenestración de Baldomero Espartero como hombre fuerte de la política española, tras un levantamiento acaecido entre mayo y julio de 1843 (levantamiento que acabó con el exilio del regente precisamente en Londres), sirvió para acabar de tranquilizar a quienes un par de años antes se habían organizado y movilizado para defender la esclavitud, tanto en La Habana como en Madrid y en Barcelona. Pronto se esfumó la posibilidad de que terminase la incesante llegada (ilegal, eso sí) de nuevos africanos esclavizados a Cuba o a Puerto Rico, o de que el gobierno progresista accediese a debatir sobre la abolición de la esclavitud en ambas islas. Los propósitos de Turnbull de que España procediese a liberar a todos los africanos que habían llegado clandestinamente a Cuba, después de 1820, quedaron así archivados en el cajón del olvido. Mientras tanto, el comercio ilegal y clandestino de esclavos se mantuvo en dicha isla durante otros veinticinco años más, hasta 1867. De hecho, después de que acabasen las entradas de más africanos esclavizados en Brasil, en 1851 , la isla de Cuba quedó como el único territorio americano al que todavía seguía arribando nuevos esclavos.

\section{Más allá del trienio esparterista}

La movilización patricia registrada en Barcelona durante 1841 no fue la única que tuvo lugar en la capital catalana por similares motivos. Entre 1857 y 1858 hubo, por ejemplo, una nueva campaña de agitación motivada por una acción del Tribunal Mixto de Sierra Leona, que había condenado a la tripulación de la goleta Conchita por su dedicación al ilegal comercio de esclavos. Se trataba de un buque mercante matriculado en la

53 Nelson, 2017. 
capital catalana y de una expedición organizada por el comerciante José Vidal Ribas, la cual terminó cuando el crucero británico Firefly la detuvo mientras estaba anclada frente a Ajuda, el 27 de agosto de 1857. Los principales protagonistas de aquella otra campaña fueron los periodistas e intelectuales Juan Mañé Flaquer y Modesto Costa Turell, a los que Albert Garcia califica como «hombres nada marginales entre las élites barcelonesas de la década central del siglo XIX» ${ }^{54}$. Dicho autor ha analizado una serie de artículos que ambos autores (y sobre todo Mañé) publicaron en el Diario de Barcelona tras la susodicha condena, sugiriendo que su lectura e interpretación deben hacerse en el contexto de las rivalidades imperiales que se estaban produciendo entonces, tanto en África como en Asia. De las múltiples aristas de aquel caso quiero centrarme sólo en una: En la airada crítica que Juan Mañé Flaquer realizó de la política británica de persecución de la trata. Dicho autor denunció singularmente la forzada interpretación que los británicos hacían del Tratado bilateral de 1835, el cual no sólo permitía a los oficiales de la Royal Navy inspeccionar cualquier buque de bandera española sino poderlo conducir además ante el Tribunal de Sierra Leona simplemente por llevar a bordo una cantidad sospechosamente alta de agua o de comida. Frente a los intereses y a la política de los británicos en las costas africanas, Mañé reclamaba una enérgica política española que defendiese al comercio y a los comerciantes españoles (entre ellos a los catalanes) en el golfo de Guinea, donde España disponía, además, de unos enclaves insulares que estaban bajo su soberanía ${ }^{55}$. Aquella campaña tuvo tal éxito que una entidad de la ciudad, la Sociedad Económica Barcelonesa de Amigos del País, elevó en 1858 una petición a la reina Isabel II mediante la que pidió al gobierno, entre otras cosas, que contemplase la renegociación del tratado bilateral de 1835 . Una petición no muy diferente de alguna de las demandas expresadas en 1841 y 1842 por las Juntas de Comercio de Cataluña y de Madrid.

Hubo, al menos, dos momentos más en los que la ciudad de Barcelona registró sendas campañas en defensa de la institución de la esclavitud en Cuba y Puerto Rico. El primero tuvo lugar en 1869, también con un protagonismo destacado de Juan Mañé Flaquer. Se trataba entonces de una campaña de respuesta frente al Grito de Yara, proclamado en las cercanías de Camagüey el 10 de octubre de 1868. Una acción que había dado

54 García Balañà, 2008.

55 Ibidem. 
inicio a una guerra por la independencia de Cuba en la que sus líderes procedieron a la inmediata liberación de sus esclavos (a los que conminaron, eso sí, que defendiesen dicha libertad con las armas y frente al ejército español). La campaña en defensa de la esclavitud en la mayor de las Antillas (y el rechazo a cualquier tipo de eventuales reformas que pudiesen modificar el statu quo colonial), que pronto se lanzó desde Barcelona estuvo subsumida en una más amplia campaña, política y militar, en defensa de la españolidad de Cuba y en contra de cualquier tipo de reformas que modificasen el statu quo colonial. En ese contexto, más de cien hombres de negocios de Barcelona se reunieron el 8 de enero de 1869 y acordaron dirigirse a la Diputación Provincial de Barcelona para que adoptase acciones enérgicas y concretas contra los independentistas cubanos. Reunida tres días después una delegación de dichos empresarios con los diputados provinciales, unos y otros acordaron la creación de un «cuerpo de voluntarios catalanes», impulsado por la Diputación de Barcelona aunque financiado con aportaciones particulares de los integrantes del patriciado urbano. El gobierno español rechazó, de entrada, aquella iniciativa surgida desde la capital catalana y sólo acabó cediendo a las presiones que le llegaban desde dicha ciudad un mes más tarde. No le tembló la pluma al entonces director del Diario de Barcelona, Juan Mañé y Flaquer, intelectual orgánico de los conservadores catalanes, para denunciar la tibieza del gobierno español «al no consentir que se hiciesen los alistamientos» de dichos voluntarios, «al no permitir que el espíritu patriótico de Cataluña [...] se manifestara vivo y ardiente de manera que el eco de estas manifestaciones llegase hasta los rebeldes de Cuba y les convenciera de que España está dispuesta a todo linaje de sacrificios para conservar a sus preciosas Antillas». Se lamentaba Mañé particularmente del tiempo perdido por el inicial rechazo del gobierno, al afirmar que «un mes perdido vale por diez acciones de guerra ganados por los sublevados» ${ }^{56}$.

Igual que sucediera en 1841, nuevamente en 1869 la burguesía barcelonesa actuó como la punta de lanza de una iniciativa que buscaba mantener tanto la sujeción de Cuba bajo la soberanía española como el statu quo colonial vigente, con la consiguiente protección de la esclavitud en la Isla. Una iniciativa que fue imitada o secundada, después, por otras ciudades portuarias españolas como Bilbao, Santander, Cádiz o Gijón, desde donde zarparon otros batallones de voluntarios, quienes lucharon en Cuba codo a

56 Diario de Barcelona, 18.02.1869, pp. 1539-1540. 
codo con los soldados del ejército español. En ningún otro lugar de la península se movilizaron, sin embargo, tantos hombres como en Barcelona, desde donde se llegaron a enviar a un total de 3.600 jóvenes catalanes a la gran Antilla ${ }^{57}$.

Un último momento en el que pudo apreciarse, también en la capital catalana, una nueva e intensa campaña en defensa de la esclavitud fue a partir de diciembre de 1871, cuando se creó el Círculo Hispano Ultramarino de Barcelona. Cabe señalar que aunque aquel movimiento de los Círculos Hispano Ultramarinos había nacido un mes antes, en Madrid, y que si bien se llegaron a crear activos Centros, Casinos o Círculos Hispano Ultramarinos en las principales ciudades españolas, lo cierto es que el círculo barcelonés merece una atención especial ${ }^{58}$. Una atención que va más allá de los objetivos de este artículo y que realizó parcialmente, en su día, Jordi Maluquer de Motes ${ }^{59}$. Sabemos que el Círculo Hispano Ultramarino de Barcelona se destacó, singularmente, por su abierta defensa de la esclavitud en las Antillas. Así lo hizo, por ejemplo, con motivo de la discusión registrada en el Congreso de los Diputados sobre la abolición de la esclavitud en Puerto Rico, a finales de 1872 y principios de 1873. El círculo barcelonés lideró entonces una activa e intensa campaña anti-abolicionista que fue secundada, por cierto, por las principales organizaciones de la burguesía catalana del momento como el Fomento de la Producción Nacional, el Instituto Industrial de Cataluña y el Instituto Agrícola Catalán de San Isidro.

También entonces, tal como había sucedido en 1841 con el Tribunal de Comercio de Barcelona y con la Junta de Comercio de Cataluña, las principales corporaciones económicas de la ciudad mostraron su apoyo a las tesis anti-abolicionistas defendidas con vehemencia por algunos de los principales indianos de la ciudad, enriquecidos en su mayoría en la Cuba esclavista. Me refiero, entre otros, a Juan Güell Ferrer, Antonio López y López, José Antonio Salom Jacas, José María Serra Muñoz, José Ferrer Vidal, José Canela Raventós y Tomás Ribalta Serra, miembros destacados de la junta directiva del Círculo Hispano Ultramarino de Barcelona. Todos ellos (igual que habían hecho, durante el Trienio Esparterista, indianos de una generación anterior a la suya como Jaime Badia, Jaime Tau-

57 Rodrigo, 2009, pp. 321-333.

58 Para el círculo de Sevilla, véase Romero, 1988; para el de Valencia, cfr. Piqueras, 1992, pp. 403-416.

59 Maluquer de Motes, 1971, 1974, y 1986, pp. 327-331. 
lina, Jaime Torrents, Miguel Biada o José Xifré) se organizaron entonces para presionar a favor del mantenimiento de la esclavitud en las Antillas españolas así como para conseguir un estado en la opinión pública favorable a sus argumentos.

\section{Conclusiones}

España fue el último país europeo en abolir la institución de la esclavitud en sus colonias americanas. Lo hizo, como señalé al principio, en 1873, en Puerto Rico, y en 1886, en Cuba. Fue también en un territorio sujeto a la soberanía española, en la isla de Cuba, donde se desembarcó el último africano esclavizado de todo el continente americano. Una cronología tan tardía, tanto en la supresión del comercio de esclavos como en la abolición de la esclavitud, debe explicarse, siquiera de forma parcial, por la fortaleza de los partícipes, beneficiarios y defensores de la trata africana y de la esclavitud, también en España, y por su exitosa capacidad de presión sobre unas autoridades políticas y militares que con frecuencia se mostraron bastante receptivas a sus argumentos. He analizado aquí quienes fueron los principales defensores del comercio de esclavos y de la esclavitud en la ciudad de Barcelona, prestando atención tanto a sus argumentos como a sus trayectorias vitales. La coyuntura elegida, los años de la regencia de Baldomero Espartero, fueron claves para apreciar la fortaleza de aquellos sectores anti-abolicionistas cuyos actos de presión alcanzaron finalmente sus objetivos. Los impulsores y líderes de aquellas campañas pro-esclavistas formaron parte de la gran burguesía barcelonesa y, en su mayoría, se habían enriquecido previamente en Cuba, vinculados tanto a la explotación del trabajo esclavo como al comercio ilegal de cautivos africanos.

\section{Bibliografía}

ARnalte, Arturo, El Tribunal mixto anglo-español de Sierra Leona 1819-1873, Tesis Doctoral, Universidad Complutense de Madrid, 1992.

ARroyo JiMÉnEZ, Paloma, «La sociedad abolicionista española, 1864-1886», en Solano, Francisco de Paula; Guimerá, Agustín (coords.), Esclavitud y derechos humanos: la lucha por la libertad del negro en el siglo XIX. Actas del Coloquio Internacional sobre abolición de la esclavitud, Madrid 2-4 diciembre 1986, Madrid, pp. 169-182. 
Bahamonde, Ángel; CAyuela, José, Hacer las Américas. Las élites coloniales españolas en el siglo XIX, Madrid, Alianza, 1992.

Blasco, Yolanda, Epistolari de Jaume Badia. El pensament bancari en el segle XIX, Torredembarra, Arxiu Municipal de Torredembarra, 2009.

Clarence-Smith, William, «The economic dynamics of Spanish colonialism in the nineteenth and twentieth centuries», Itinerario, 15, 1, 1971.

Colección de varios documentos del expediente que existe en la Junta de Comercio de esta capital referente al proyecto de emancipación de los esclavos negros de las Antillas Españolas, Madrid, Imprenta Nacional, 1842.

Cusachs i Corredor, Manuel, Miquel Biada i Bunyol (1789-1848). L'home, l'indià $i$ el promotor del tren de Barcelona a Mataró, Mataró, edición del autor, 2007.

El Youssef, Alain, Imprensa e Escravidao: Política e tráfico negreiro no imperio do Brasil (Río de Janeiro, 1822-1850), Tesis Doctoral, Universidade de Sao Paulo, 2010.

FraderA, Josep Maria, Indústria i mercat, Barcelona, Crítica, 1987.

FraderA, Josep Maria, «Opio y negocio, o las desventuras de un español en China», en Gobernar Colonias, Barcelona, Península, 1999.

Franco, José Luciano, Comercio clandestino de esclavos, La Habana, Editorial de Ciencias Sociales, 1980

GARCía BALAÑà, Albert, «Antislavery before Abolitionism. Network and Motives in Early Liberal Barcelona, 1833-1844», en FrADERA, Josep Maria; Schmidt-Nowara, Christopher (eds.), Slavery and Antislavery in Spain's Atlantic Empire, New York, Berghahn Books, 2013, pp. 229-255.

García Balañà, Albert, «"El comercio español en África” en la Barcelona de 1858, entre el Caribe y el mar de la China, entre Londres y París», Illes i Imperis, números 10-11, 2008, pp. 167-186.

Ikunde. Barcelona, metrópoli colonial, Barcelona, Museu de les Cultures del Món, 2016.

Juncosa I GuRguí, Xavier, «Jaume Torrents Serramalera, el esclavista oculto» en Rodrigo, Martín; Chaviano, Lizbeth (eds), Negreros y esclavos. Barcelona y la esclavitud Atlántica (ss. XVI-XIX), Barcelona, Icaria, 2017, pp. 159-188.

LuCEna Salmoral, Manuel, «El derecho de coartación del esclavo en la América española», Revista de Indias, 59 (216), 1999, pp. 357-374.

MALuQuer De Motes I Bernet, Jordi, «El problema de la esclavitud y la revolución de 1868», Hispania, vol. XXXI, 1971, pp. 55-76.

MALUQUER DE Motes, Jordi, «La burgesia catalana i l'esclavitud colonial: modes de producció i pràctica política», Recerques, núm. 3, 1974, pp. 83-136.

MAluquer De Motes i Bernet, Jordi, «Abolicionismo y resistencia a la abolición en la España del siglo XIX», Anuario de Estudios Americanos, vol. XLIII, 1986, pp. 311-331. 
Martín Corrales, Eloy, «Esclavos negros en la España del siglo XIX», en RoDRIGO, Martín; CózAR, M. del Carmen (eds.), Cádiz y el tráfico de esclavos. De la legalidad a la clandestinidad, Madrid, Silex, 2018, pp. 47-69.

Moreno Fraginals, Manuel, El Ingenio. Complejo económico social cubano del azúcar, La Habana, Editorial de Ciencias Sociales, 1978.

Morgado, Arturo, «La participación de Cádiz en el comercio de esclavos durante la época moderna (1650-1800)», en Rodrigo, Martín; CózAR, M. del Carmen (eds.), Cádiz y el tráfico de esclavos. De la legalidad a la clandestinidad, Madrid, Silex, 2018, pp. 21-46.

Murray, David, Odious commerce: Britain, Spain and the abolition of the Cuban slave trade, Cambridge University Press, 1990.

NELSON, Jennifer, «Slavery, race and conspiracy: The HMS Romney in nineteenthcentury Cuba», Atlantic Studies, 14:2, 2017, pp. 174-195.

PERMANYeR UGARTEMENDiA, Ander, La participación española en la economía del opio en Asia Oriental tras el fin del Galeón, Tesis Doctoral, Universitat Pompeu Fabra, 2013.

Piqueras ARenas, José Antonio, La revolución democrática (1868-1874). Cuestión social, colonialismo y grupos de presión, Madrid, Ministerio de Trabajo, 1992.

RAmón de SAN Pedro, José María, Banqueros románticos catalanes (edición a cargo de Enrique Faes), Madrid, Marcial Pons, 2017.

Representaciones de la Junta de Comercio de Cataluña e informes que acompañó relativamente al proyecto que ha propuesto el gobierno inglés de emancipación de esclavos en las colonias españolas, Barcelona, Imprenta de los herederos de Roca, 1841.

RoDrigo y AlHARILlA, Martín, «Cataluña y el colonialismo español (18681899)», en CAlatayud, Salvador; Millán, Jesús; Romeo, Mari Cruz (eds.): Estado y periferias en la España del siglo XIX. Nuevos enfoques, Valencia, PUV, 2009, pp. 315-356.

Rodrigo y AALHARILla, Martín (ed.), Les bases colonials de Barcelona, 1765-1968, Barcelona, Museu d'Història de Barcelona, 2013.

Romero CASTAÑón, Eloy, «El Centro Hispano-Ultramarino de Sevilla y la guerra de Cuba (1872-1881)», en DDAA: Temas de Historia Militar. 2. ${ }^{\circ}$ Congreso de Historia Militar. Zaragoza, 1988, Zaragoza, vol. III, pp. 213-230.

SAnjurJo, Jesús, Abolitionism and the End of the Slave Trade in Spain's Empire (1800-1870), PhD Dissertation, University of Leeds, 2018.

SCHMIDT-NowARA, Christopher, «National Economy and Atlantic Slavery: Protectionism and Resistance to Abolitionism in Spain and the Antilles, 18541874», Hispanic American Historical Review, vol. 78, núm. 4, 1998, pp. 603-629.

SCHMIDT-NowARA, Christopher, Empire and Antislavery. Spain, Cuba and Puerto Rico, 1833-1874, University of Pittsburgh Press, 1999. 
SCHUBERT, Adrian, Espartero, el pacificador, Barcelona, Galaxia Gutenberg, 2018.

SeCo Serrano, Carlos, «Espartero y Cuba: Entre Inglaterra y Norteamérica», en Homenaje a Carlos Pérez Bustamante, Madrid, Instituto Gonzalo Fernández de Oviedo, 1969, pp. 581-605.

YASHIMA, Yukari, «Los indianos y sus redes personales y empresariales en el colonialismo español del siglo XIX: el caso de José Xifré Casas», Illes i Imperis, $19,2017,125-144$.

\section{Financiación}

Este artículo es uno de los resultados del proyecto de investigación financiado por la Agencia Estatal de Investigación-Ministerio de Ciencia e Innovación PID2019-105204GB-I00.

\section{Datos del autor}

Martín Rodrigo y Alharilla es Profesor Titular de Historia Contemporánea en el Departamento de Humanidades de la Universitat Pompeu Fabra (Barcelona), miembro de la Unidad Asociada del CSIC Grupo de Estudios de Asia y Pacífico y académico correspondiente extranjero de la Academia de Historia de Cuba. Investigador principal del proyecto colectivo de investigación «Memoria y lugares de memoria de la esclavitud y el comercio de esclavos en la España contemporánea». Entre sus últimos libros destacan, como autor: Los Goytisolo, una próspera familia de indianos (Madrid, Marcial Pons, 2016); La marina mercante de vapor en Barcelona, 1834-1914 (Barcelona, Museo Marítimo de Barcelona, 2017); Un hombre, mil negocios. La controvertida historia de Antonio López, marqués de Comillas (Ariel, Barcelona, 2021), y como coautor y coeditor: Negreros y esclavos. Barcelona y la esclavitud atlántica (SS. XVI-XIX) (Barcelona, Icaria, 2017), y Cádiz y el tráfico de esclavos. De la legalidad a la clandestinidad (Madrid, Sílex, 2018). 